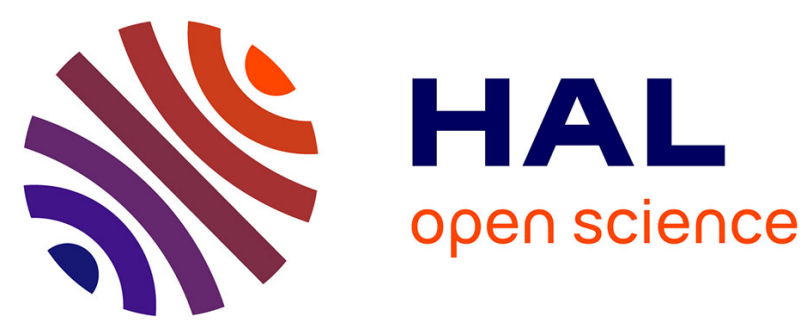

\title{
Hybrid gold nanoparticle-quantum dot self-assembled nanostructures driven by complementary artificial proteins
}

Maxence Fernandez, Agathe Urvoas, Pascale Even-Hernandez, Agnès Burel, Cristelle Meriadec, Franck Artzner, Tahar Bouceba, Philippe Minard, Erik Dujardin, Valérie Marchi

\section{To cite this version:}

Maxence Fernandez, Agathe Urvoas, Pascale Even-Hernandez, Agnès Burel, Cristelle Meriadec, et al.. Hybrid gold nanoparticle-quantum dot self-assembled nanostructures driven by complementary artificial proteins. Nanoscale, 2020, 12 (7), pp.4612-4621. 10.1039/C9NR09987E . hal-02462978

\section{HAL Id: hal-02462978 https://hal.science/hal-02462978}

Submitted on 31 Jan 2020

HAL is a multi-disciplinary open access archive for the deposit and dissemination of scientific research documents, whether they are published or not. The documents may come from teaching and research institutions in France or abroad, or from public or private research centers.
L'archive ouverte pluridisciplinaire HAL, est destinée au dépôt et à la diffusion de documents scientifiques de niveau recherche, publiés ou non, émanant des établissements d'enseignement et de recherche français ou étrangers, des laboratoires publics ou privés. 


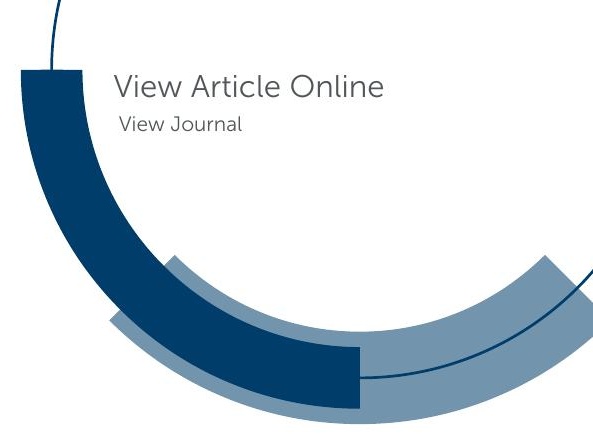

\section{Accepted Manuscript}

This article can be cited before page numbers have been issued, to do this please use: M. Fernandez, A. Urvoas, P. Even-Hernandez, A. Burel, C. Meriadec, F. Artzner, T. Bouceba, P. Minard, E. Dujardin and V. Marchi, Nanoscale, 2020, DOI: 10.1039/C9NR09987E.
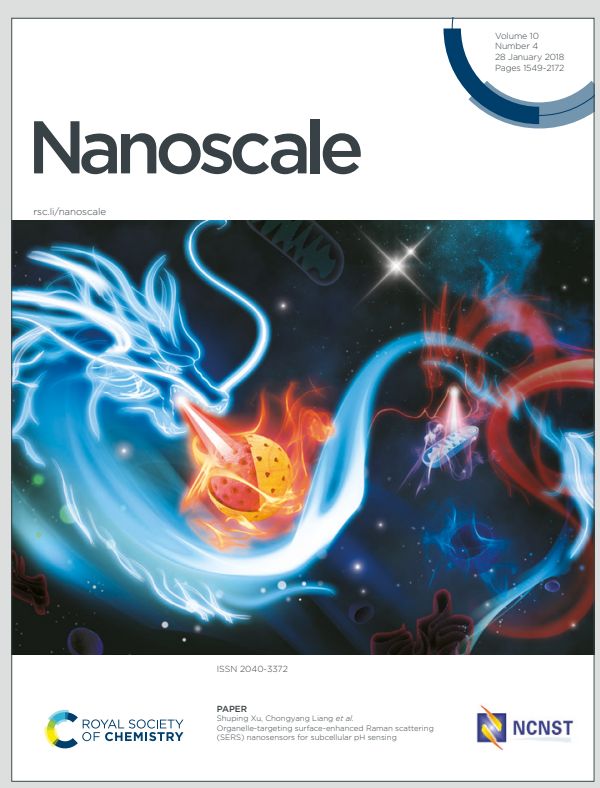

This is an Accepted Manuscript, which has been through the Royal Society of Chemistry peer review process and has been accepted for publication.

Accepted Manuscripts are published online shortly after acceptance, before technical editing, formatting and proof reading. Using this free service, authors can make their results available to the community, in citable form, before we publish the edited article. We will replace this Accepted Manuscript with the edited and formatted Advance Article as soon as it is available.

You can find more information about Accepted Manuscripts in the Information for Authors.

Please note that technical editing may introduce minor changes to the text and/or graphics, which may alter content. The journal's standard Terms \& Conditions and the Ethical guidelines still apply. In no event shall the Royal Society of Chemistry be held responsible for any errors or omissions in this Accepted Manuscript or any consequences arising from the use of any information it contains. 


\section{ARTICLE}

\section{Hybrid gold nanoparticle-quantum dot self-assembled nanostructures driven by complementary artificial proteins}

Received 00th January 20xx, Accepted 00th January 20xx

DOI: $10.1039 / \times 0 \times x 00000 x$

\author{
Maxence Fernandez, ${ }^{a}$ Agathe Urvoas, ${ }^{b}$ Pascale Even-Hernandez, ${ }^{a}$ Agnès Burel,,${ }^{c}$ Cristelle Mériadec, ${ }^{d}$ Franck Artzner ${ }^{d}$ Tahar

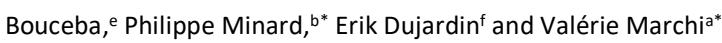

\section{Introduction}

Tailoring the properties of light down to the nanometer scale has recently benefited from two major advances: the engineering of collective oscillations of free electrons in noble metals, surface plasmons, and the quantum confinement of noble metals and semiconductors leading to robust and efficient fluorophores. Efforts to couple the field enhancement and confinement near metal nanoparticles and the highly designable fluorescence of quantum dots (QD) within hybrid nanostructures has opened new horizons for nanophotonics ${ }^{1,2}$ with promising applications in biomedical diagnosis (imaging, sensing) ${ }^{3,4}$ and therapy (optical hyperthermia), 5,6 energy saving (reduced heat production in electronic chips) ${ }^{7}$ and green production (enhanced photovoltaics). ${ }^{8}$ However, the way leading to these objectives is still facing two major challenges: the preparation of optically activated metallic and semiconductor nanoparticles (NP) of controlled size,

a. University Rennes 1, Institut of Chemical Sciences, UMR 6226 CNRS, Campus Beaulieu, F-35042 Rennes, France.

b. Institute for Integrative Biology of the Cell (I2BC), CEA, CNRS, Univ. Paris-Sud, Université Paris-Saclay, 91198 Gif-sur-Yvette Cedex, France.

c. University Rennes 1, Microscopy Rennes Imaging Center, UMS3480 BIOSIT, Campus Villejean, Rennes, France.

d. University Rennes 1, Institut de Physique de Rennes, UMR 6251 CNRS, Campus Beaulieu, F-35042 Rennes, France.

e. Sorbonne Université, CNRS, Institut de Biologie Paris-Seine (IBPS), Protein engineering platform, Molecular Interaction service, F-75005 Paris, France.

f. Groupe NanoSciences-CEMES, CNRS UPR 8011, 29 rue J. Marvig, B.P. 94347, F31055 Toulouse, France.

Electronic Supplementary Information (ESI) available: See DOI: 10.1039/x0xx00000x crystallinity and morphology and their organization into 2D and 3D higher-order architectures of well-controlled topology for functional devices.

The optoelectronic properties of these self-assembled hybrid QD-metal nanoparticle structures derive from a range of nearfield mechanisms including energy Transfer (e.g. Fluorescence resonance Energy Transfer, FRET) and field enhancement (e.g. Surface-Enhanced Raman Scattering SERS and Metal-Enhanced Fluorescence MEF) that are directly affected by structural and electrostatic parameters of the self-assembly such as interparticle Coulomb interactions, dielectric constant of the material, topology and morphology of the assembly and its constituents. Among these parameters, the interparticle distance has a tremendous effect on the optical coupling of QD with neighbouring nanoparticles within higher-order selfassembled architectures. In particular, the photoluminescence intensity of the QD is enhanced, ${ }^{9}$ diminished ${ }^{10}$ or shifted ${ }^{9}$ due to the exciton coupling between identical proximal QD or channelled towards other QD if the emission band of one type overlap the absorption band of the other. ${ }^{11}$ When QD are coupled to metal plasmonic nanoparticles, the exciton-plasmon coupling strongly depends on the interparticle distance in the NP nanostructures and the energy overlap between plasmon and exciton bands. ${ }^{9,12,13}$ The QD photoluminescence intensity can be either enhanced or attenuated due to the competition between non radiative energy transfer to plasmonic NP and the local electric field enhancement. 2,12,13 QD-metal hybrid nanostructures have been prepared using DNA strands ${ }^{13,14}$, antibodies $^{15}$ and proteins such as BSA ${ }^{16,17}$ or streptavidin ${ }^{15,18-20}$ which offer new opportunities to tailor the interparticle distance or self-assembly structure. 
In this article, we induce the specific assembly by using one representative of highly specific artificial protein pairs that is created by choosing one specific protein and selecting the pairforming partner by directed evolution. ${ }^{21}, 22$ The family of artificial repeat proteins named $\alpha$ Reps are efficiently produced as recombinant proteins with a very stable folded structure and can be easily tailored to be grafted onto metallic surfaces using metal-binding cysteine tags. Furthermore, a very large library of $\alpha$ Reps with a variable surface was built and allows to identify using directed evolution methods ${ }^{21,22}$ new proteins binding tightly and specifically to any protein target of interest. ${ }^{23} \mathrm{~A}$ specific pair of $\alpha$ Reps named A3 / $\alpha 2$ obtained previously was chosen here for its small and compact complex prone to generate 3-10 nm interparticle gaps and for its facile grafting onto metallic as well as semiconductor surfaces in order to drive the QD-QD and QD-metallic gold nanoparticle (AuNP) selforganization. We have recently demonstrated the principle of colloidal self-assembly driven by pairs of $\alpha$-Rep proteins for homogeneous ensembles of protein-capped gold nanoparticles (AuNP). ${ }^{24}$ On another hand, we have shown how to prepare stable bioactivated QD with high affinity hydrophilic ligands, 25 that we are transposing here to the $A 3$ and $\alpha 2$ proteins. Each complementary protein is tagged with a tri-cysteine tag motif at their C-terminal end and prepared at the milligram scale from small scale $E$. coli bacterial cultures. ${ }^{21} \mathrm{Next}$, the proteins are grafted onto peptide-stabilized CdSe@ZnS core-shell QD by ligand exchange. The efficiency of the protein grafting on the QD surface is demonstrated by the induction of self-assembly of complementary $\alpha$ Rep protein-grafted QD driven by the A3- $\alpha 2$ protein affinity. Finally, our method is successfully applied to the self-assembly of hybrid QD-AuNP from mixtures of complementary $\alpha$ Rep protein-grafted AuNP and QD. The extent and size of the superstructures depends on the molar ratio between the proteins and the nanoparticles used the ligand exchange step. SAXS and TEM analysis of both QD-QD and QDAuNP self-assembled ensembles reveal a highly uniform interparticle distance which is a crucial step to reduce the inhomogeneous dispersion of the optical behaviour of the hybrid superstructures. Finally their optical properties suggest that the protein pairing affects the exciton or plasmon-exciton coupling within these nanostructures.

\section{Experiment}

\section{Materials}

Hydrogen tetrachloroaurate(III) trihydrate $\left(\mathrm{HAuCl}_{4}\right)$ and tetramethylammonium hydroxide, $25 \% \mathrm{w} / \mathrm{w}$ aqueous solution (TMAOH) from Alfa Aesar; tri-sodium citrate dihydrate and chloroform from Carlo Erba Reagents; DL-Dithiothreitol, gold nanoparticles (10 $\mathrm{nm}$ diameter, OD 1, stabilized suspension in $0.1 \mathrm{mM}$ PBS, reactant free), agarose, sodium phosphate monobasic $\left(\mathrm{NaH}_{2} \mathrm{PO}_{4}\right)$, sodium chloride $(\mathrm{NaCl})$ and sodium hydroxide $(\mathrm{NaOH})$ from Sigma-Aldrich. Boric acid was purchased from Honeywell Fluka and Cys-Cys-Cys-11-aminoundecanoyl15-amino-4,7,10,13-tetraoxapentadecanoyl from PolyPeptide Laboratories or Agentide Inc. Proteins were stored at $-80{ }^{\circ} \mathrm{C}$ in
pH 7.4 phosphate buffer saline. Ultrapure Millipore water $(1,8,2$ $\mathrm{M} \Omega$ ) was used. Formvar/Carbon film 300 Preshphickefgeridsfpoth Oxford Instruments. All glassware was washed with aqua regia and rinsed with ultrapure water and ethanol. UV/Vis spectroscopic measurements were carried out using a Cary-100 UV-vis NIR spectrophotometer instrument operated by Carry UV Win (Version 3.00) software. Emission spectra were recorded on a Fluorolog-3 fluorimeter (Horiba Jobin-Yvon) operated by FluorEssence (Version 2.0.9.0).

\section{Peptide Grafting for the Stabilization of AuNP and QD}

\section{Gold nanoparticles preparation}

$5 \mathrm{~mL}$ of $11 \mathrm{nM}$ commercial suspension of $10 \mathrm{~nm} \mathrm{Au}$ nanoparticles or $16 \mathrm{~nm}$ homemade citrate-capped nanoparticles ${ }^{25}$ were incubated with an aqueous solution of Cys-Cys-Cys-11-aminoundecanoyl-15-amino-4,7,10,13-

tetraoxapentadecanoyl (C5PEG4, $7 \mu \mathrm{L}, 20 \mathrm{mM}$ ). The mixture was allowed to stand for $2 \mathrm{~h}$ and is then washed, filtered and concentrated using Amicon ${ }^{\circledR}$ Ultra $-0.5 \mathrm{~mL} 100 \mathrm{~K}$ centrifugation filters and NaP $20 \mathrm{mM} \mathrm{pH} 7.4$ buffer through multiple centrifugation cycles ( $3800 \mathrm{~g}, 2 \mathrm{~min}$ ). Typically, $230 \mu \mathrm{L}$ of 180 nM AuNP-peptide suspension were obtained.

\section{Quantum dots preparation}

The QD used in this study were commercial CdSe@ZnS core@shell nanoprisms (Qdot ${ }^{\mathrm{TM}} 655$ ITK $^{\mathrm{TM}}$ organic quantum dots, Thermo Fisher Scientific) when no indication if given. Otherwise nanospheres (Qdot TM 545 ITK TM Thermo Fisher Scientific) were also used for comparison. Water solubilization and stabilization of quantum dots was achieved according to a previously described method. ${ }^{26}$ First, $1 \mathrm{~mL}$ of $1 \mu \mathrm{M}$ commercial suspension of red quantum dots in decane was first flocculated by centrifugation to transfer the nanocrystals from decane to chloroform. For this purpose, $1 \mathrm{~mL}$ of the quantum dots suspension was separated into 5 microtubes with $800 \mu \mathrm{L}$ of $75 / 25$ methanol/isopropanol mixture and was then centrifuged (660 g, 5 minutes). The solvent was removed and the flocculated nanocrystals were redispersed in $1 \mathrm{~mL}$ of chloroform. This organic suspension was mixed successively with $70 \mu \mathrm{L}$ of $20 \mathrm{mM}$ aqueous C5PEG4 solution and $12 \mu \mathrm{L}$ of $\mathrm{TMAOH}$ at $25 \%(\mathrm{w} / \mathrm{w})$ in water. These additions induced the transfer of the nanocrystals from the organic solvent to the aqueous phase. Chloroform was removed after $15 \mathrm{~min}$ incubation and the mixture was evaporated $(60 \mathrm{mbar}, 20 \mathrm{~min}$, room temperature) to remove organic solvent traces. Peptide molecules in excess were removed by size exclusion chromatography using sephadex G-25 columns (NAP-5 from GE Healthcare) equilibrated and eluted with $\mathrm{NaP} 20 \mathrm{mM} \mathrm{pH} 7.4$ buffer. The obtained aqueous suspension of $Q D$ featured a concentration in the range of $500 \mathrm{nM}$.

\section{Protein Conjugation on AuNP and QD}

First, cysteine-tagged $\alpha$ Rep proteins were incubated at $12^{\circ} \mathrm{C}$ for $2 \mathrm{~h}$ in $100 \mathrm{mM}$ DTT in order to reduce their intra and interprotein disulfide bonds. The excess DTT was removed by centrifugal elution through desalting column (Zeba Spin 
Desalting Columns, 7K MWCO) with NaP 20 mM pH 7.4 buffer. Next, peptide-stabilized nanoparticles were functionalized by incubating them (overnight, $12^{\circ} \mathrm{C}$ ) with 100 and 30 molar equivalents of proteins ( $\alpha 2$ or $A 3$ ) for $Q D$ and AuNP respectively. After incubation, the protein excess was removed by using an ultrafiltration unit Amicon ${ }^{\circledR}$ Ultra - $0.5 \mathrm{~mL}$ with a 30,000 molecular weight cutoff (MWCO) at $7200 \mathrm{rpm}$ for $2 \mathrm{~min}$ and washing 5 times with NaP $20 \mathrm{mM} \mathrm{pH} 7.4$ buffer. The purified QD-protein were finally redispersed in $\mathrm{NaP} 20 \mathrm{mM} \mathrm{pH} 7.4$ buffer

\section{Agarose Gel Electrophoresis}

Agarose gel electrophoresis was employed to monitor the charge and size variations for semiconductor and gold nanoparticles using a Gel XL Ultra V-2 (Labnet International, Inc., USA) horizontal electrophoresis system. The agarose gel was prepared dissolving agarose $(500 \mathrm{mg})$ in borate $20 \mathrm{mM} \mathrm{pH}$ 8 buffer $(100 \mathrm{~mL})$ at $90^{\circ} \mathrm{C}$. This solution was then poured into four $53 \mathrm{~mm} \times 53 \mathrm{~mm}$ gel trays or two $130 \mathrm{~mm} \times 59 \mathrm{~mm}$ trays within a gel caster. The gel was run in borate $20 \mathrm{mM} \mathrm{pH} 8$ buffer for 20 to 45 minutes using a voltage of $9 \mathrm{~V}$ per $1 \mathrm{~cm}$ of gel and revealed with a UV light $(365 \mathrm{~nm})$.

\section{A3/AuNP and A3/QD stoichiometry determination}

The AuNP-A3 and QD-A3 were prepared and purified from the A3 protein excess according to the methods described above. The concentrations of Au NP and QD were then determined by ICP-MS measurements. The A3/AuNP and A3/QD stoichiometries were determined by fluorescence emission measurements after dissolving the inorganic core of the nanoparticles while preserving the proteins as follows. The dissolution of the AuNP nanoparticles, $32 \mu \mathrm{L}$ AuNP-A3 (90 nM) was obtained by incubation with $16 \mu \mathrm{L}$ saturated KCN during 1 hour. The dissolution of the QD-A3 was realized by incubation in acidic $\mathrm{HCl}$ solution during 12 hours according to the literature. ${ }^{27}$ Standard $A 3$ solutions at different concentrations from a stock solution (concentration $37 \mu \mathrm{M}$ ) were prepared in $\mathrm{Na}$ Phosphate buffer ( $\mathrm{pH}$ 7.4) and the fluorescent intensity v.s. concentration was measured. According to the standart curve, the A3 concentration was obtained by measuring the fluorescent intensities of the solution resulting from the AuNPA3 or QD-A3 dissolution.

\section{Transmission Electron Microscopy (TEM)}

The 300 mesh carbon coated nickel grids were placed for $1 \mathrm{~min}$ on top of a $40 \mu \mathrm{L}$ sample droplet and dried up with paper. Examination was performed with JEOL 1400 transmission electron microscope operated at $120 \mathrm{kV}$ supplied with GATAN Orius 1000 camera. Particle sizes and interparticle distances were determined from TEM micrographs using the ImageJ Software.

\section{Surface Plasmon Resonance (SPR)}

Binding experiments and kinetics assays were carried out at $25^{\circ} \mathrm{C}$ using a BIACORE 3000 (GE Healthcare) of the Platform of Molecular Interactions of the Institute of Biology Paris Seine
(IBPS, Sorbonne University). aRep proteins and BSA $_{\text {A }}$ were immobilized on CM5 sensor-chip (carboxyphiethylated dextPân through covalent amidation to the primary amine groups. For the immobilization step, the solutions of $\alpha 2$ and $A 3$ (200 nM) and a solution of $50 \mu \mathrm{g} \cdot \mathrm{ml}^{-1}$ of BSA, prepared in $10 \mathrm{mM}$ sodium acetate buffer adjusted to a $\mathrm{pH}$ adapted to the $\mathrm{pl}$ of each protein ( $\mathrm{pH} 5.0$ for $\mathrm{A} 3, \mathrm{pH} 4.5 \mathrm{BSA}$ and $\mathrm{pH} 5.5$ for $\alpha-2$ ), were injected at $10 \mathrm{~mL} \cdot \mathrm{min}^{-1}$. A contact time of 7 min was used to obtain high level of immobilization quantified as follows: 3,900 RU (Resonance Units), 11,600 RU and $1500 \mathrm{RU}$ for A3 on flow cell two (FC2), BSA on FC3 and $\alpha 2$ on FC4 respectively. FC1 was left blank as a reference surface for non-specific binding and refractive index variations. This immobilization step was followed by the injection of $1 \mathrm{M}$ ethanolamine $\mathrm{HCl} \mathrm{pH} 8.4$ to saturate the free residual amine groups. For binding experiments, a $2.3 \mathrm{nM}$ solution of QD- $\alpha 2$ in HBS-EP Buffer (GE Healthcare, HEPES $10 \mathrm{mM}$ pH 7.4, NaCl $150 \mathrm{mM}$, EDTA $3 \mathrm{mM}$, P20 0.005\%) was flown over FC1 for blank, FC2 for A3, FC3 for BSA and FC4 for $\alpha 2$ at $5 \mu$ L.min-1 for $5 \mathrm{~min}$. Kinetic measurements were performed by injecting several concentrations of $\alpha 2$ (between 0 and $2.4 \mathrm{nM}$ ) over the A3 surface at a flow rate of $5 \mu \mathrm{L}$. $\mathrm{min}^{-1}$ with a $5 \mathrm{~min}$ association phase and a $8 \mathrm{~min}$ dissociation phase corresponding to the injection of the buffer solution. After each assay, the sensorchip was regenerated by performing one injection of Glycine$\mathrm{HCl}$ buffer $\mathrm{pH} 1.5$ at $30 \mu \mathrm{L}$. $\mathrm{min}^{-1}$ for 30 seconds or two injections of Glycine- $\mathrm{HCl}$ buffer $\mathrm{pH} 2.0$ at $30 \mu \mathrm{L} . \mathrm{min}^{-1}$ for 30 seconds. All experiments were performed in triplicate.

\section{Preparation of nanoparticles mixtures}

For the preparation of $Q D \bullet Q D$ or hybrid $Q D \bullet A u N P$ selfassembled nanostructures, suspensions of freshly prepared protein-QD or protein-AuNP conjugates were used the same concentration: $96 \mathrm{nM}$ for $\mathrm{QD} \bullet A u N P$ or $100 \mathrm{nM}$ for $\mathrm{QD} \bullet \mathrm{QD}$. Mixtures of these complementary populations were prepared with a final volume of $12 \mu \mathrm{L}$ for $\mathrm{QD} \bullet A u N P$ or $30 \mu \mathrm{L}$ for $\mathrm{QD} \bullet \mathrm{QD}$, adjusting volumes of each suspension to obtain particle$\alpha 2$ :particle-A3 volume ratios of 5:1, 2:1, 1:1, 1:2, and 1:5. The same procedure was applied to the preparation of QD$\alpha 2 / A u N P-\alpha 2$ non-specific mixtures, QD-A3/AuNP- $\alpha 2$ mixture incubated with an excess of free $\alpha 2$ protein or free $A 3$ protein (adding 100 molar equivalents) as a competition test. The mixtures were gently agitated before their incubation during 12 hours at $12^{\circ} \mathrm{C}$. Finally an excess of free protein was added after this incubation on the $Q D \bullet Q D$ or hybrid $Q D \bullet A u N P$ selfassembled nanostructures as a reversibility test.

\section{Nanoparticles concentration determination}

The concentrations of QD in suspensions were calculated as described by Jasieniak et al., ${ }^{28}$ relying on the first absorption peak energy $\left(E_{1 S}\right)$ in order to calculate the $Q D$ absorption coefficient

$$
\varepsilon_{1 S}=155507+6.67054 \times 10^{13} \times e^{-E_{1 S} / 0.10551} .
$$

QD concentration was then determined by using the absorbance of the first absorption peak and its half-width-halfmaximum, allowing a rescaling of the concentration from the 
nominal size distribution of the samples. The AuNP concentration was calculated from their absorption coefficient at $520 \mathrm{~nm}: \ln \varepsilon_{\lambda_{L S P}}=3.32111 \times \ln D+10.80505$ with $\mathrm{D}$, the core diameter of the gold nanoparticles measured by TEM, according to Liu et al. ${ }^{29}$

\section{Small Angle X-Ray Scattering (SAXS)}

Small Angle X-ray Scattering was collected with Pilatus 300k detector (dectris) mounted on home-made Guinier setup based on a CuK $\alpha$ microsource $(\lambda=1.541 \AA$ ) from Xenocs. The sample to detector distance $(277 \mathrm{~mm})$ has been calibrated by using silver behenate. The X-ray patterns were therefore recorded for a range of reciprocal spacing $q=4 \pi \sin \theta / \lambda$ from $0.01-1.75 \AA^{-1}$ where $\theta$ is the diffraction angle. The acquisition time was 1 hour. The scattering intensities as a function of the radial wave vector were determined by circular integration. ${ }^{10}$

\section{Results and discussion}

QD-protein and AuNP-protein dispersions are prepared by a ligand exchange process in the presence of a protein excess as shown in Fig. 1a. The morphological and optical properties of the CdSe@ZnS core@shell quantum dots and the gold nanoparticles are summarized in Fig. S1 and S2. The AuNP and QD have an average diameter of $8.0 \pm 0.9 \mathrm{~nm}$ and $8.9 \pm 1.4 \mathrm{~nm}$ respectively. Their colloidal stability is preserved in buffered medium at $\mathrm{pH} 7.4$ using an optimized tricystein PEGylated ligand. ${ }^{26,30}$ The 8-nm diameter AuNP exhibit a localized surface plasmon resonance (LSPR) at $520 \mathrm{~nm}$ (black curve) and the QD exhibit an intense red emission band at $655 \mathrm{~nm}$ (red curve). Upon protein grafting, the fluorescence efficiency of the watersoluble QD-C5PEG4 is reduced by $35 \%$ but the emission at 655 $\mathrm{nm}$ does not undergo any spectral shift. The AuNP absorption band at $520 \mathrm{~nm}$ is fully preserved (Fig. 1c).

The titration of the QD-C5PEG4 with an increasing amount of protein has been monitored by agarose gel electrophoresis
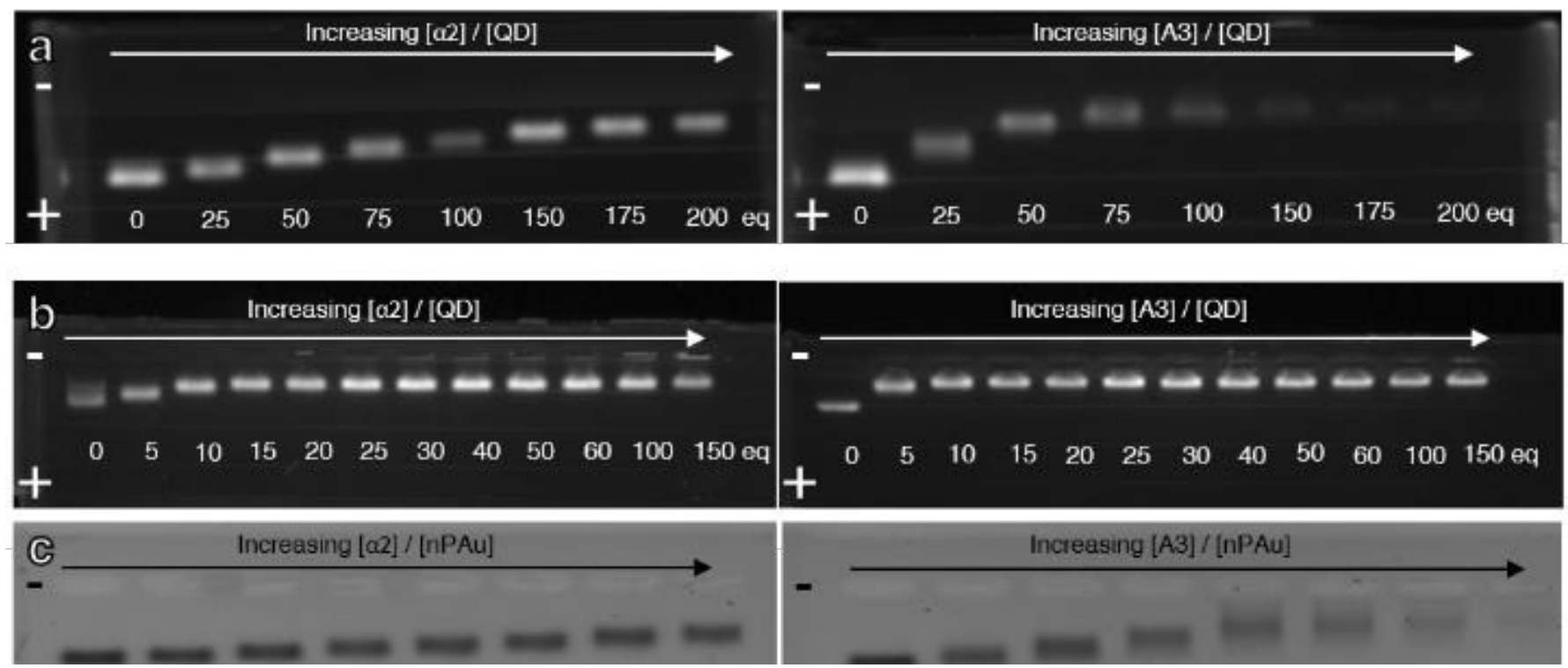

Fig. 2 Agarose gel electrophoresis of peptide-stabilized (a) 9-nm $Q D^{655}$, (b) 2.5-nm QD 545 and (c) 8-nm AuNP incubated with increasing amounts of $\alpha 2$ (left) or A3 (right). The buffer used is at $\mathrm{pH} 8$. 
migration distances are shorter than the corresponding ones for $\mathrm{A} 3$, which is attributed to the smaller size and net charge at $\mathrm{pH}$ 8 compared to A3. ${ }^{24}$ Additionally, A3-grafted nanoparticles tend to form short trails in the agarose gel. This can be attributed to the propensity of A3 to dimerize at high concentrations, ${ }^{21,24}$ which favors interparticle interaction within the highly concentrated spot of particles deposited on the gel but can also alter the effective protein/particle stoichiometry if one grafted A3 dimerizes with one free $A 3$.

\begin{tabular}{cccccc}
\hline $\mathbf{N P}$ & $\boldsymbol{A}^{N \boldsymbol{N P}}\left(\boldsymbol{n m ^ { 2 }}\right)$ & $\boldsymbol{N}_{\propto 2}^{\text {sat }}$ & $\boldsymbol{N}_{A 3}^{\text {sat }}$ & $\boldsymbol{A}_{\propto 2}^{N P}\left(\boldsymbol{n m}^{2}\right)$ & $\boldsymbol{A}_{A 3}^{N P}\left(\boldsymbol{n m} \boldsymbol{m}^{2}\right)$ \\
\hline $8.9 \mathrm{~nm}$ QD & 475 & $\geq 200 \pm 13$ & $100 \pm 13$ & $\geq 2.4 \pm 0.2$ & $4.8 \pm 0.6$ \\
$2.5 \mathrm{~nm}$ QD & 38 & $15 \pm 3$ & $10 \pm 3$ & $2.5 \pm 0.4$ & $3.8 \pm 0.9$ \\
$8 \mathrm{~nm}$ AuNP & 384 & $\geq 200 \pm 13$ & $75 \pm 13$ & $\geq 1.9 \pm 0.2$ & $5.1 \pm 0.7$ \\
\hline
\end{tabular}

Table 1 Summary of geometrical data about the NP-protein: $A^{N P}$ designs the area of the NP considered as a cube, $N_{\alpha 2}^{\text {sat }}$ corresponds to the maximal number of protein grafted on the NP surface extracted from the electrophoresis gel when the plateau is reached. $A_{\text {prot }}^{N P}=A^{N P} / N_{\text {prot }}^{\text {sat }}$ is the corresponding area for one grafted protein.

As summed up in Table 1, the maximal number of protein grafted on the NP surface scales with the surface area of the nanoparticles, $A^{N P}$.

The proteins can be as approximated to two blocks of respectively $\left(2.8 \times 2.4 \times 4.3 \mathrm{~nm}^{3}\right)$ size for $\alpha 2$ and of $\left(3 \times 3 \times 6 \mathrm{~nm}^{3}\right)$ size for A3. As expected from their relative sizes, the corresponding area of each grafted protein, denoted $A_{\text {prot }}^{N P}$ decreases with the size of the protein. The area of one grafted A3 protein is found to be around 4 to $5 \mathrm{~nm}^{2}$ which is significantly smaller than the expected $A 3$ size ( $m$ in area of $9 \mathrm{~nm}^{2}$ ) and therefore is hardly compatible with a compact monolayer of $A 3$ proteins. This observation suggests that the surface binding creates an effective high local concentration of A3 leading to the formation of a double layer of $A 3$ as this protein is known to form $\mathrm{A} 3 \bullet A 3$ dimers when concentrated. This does not prevent the subsequent $A 3 \bullet \alpha 2$ pairing as the latter complex is much more stable. ${ }^{23}$ To get a more quantitative evaluation of the protein/particle stoichiometry, the amount of bound proteins was titrated after dissolution of the inorganic core of the NPprotein conjugates while preserving the proteins by using the intrinsic fluorescence intensity of the $A 3$ protein. In the case of A3 protein, AuNP-A3 conjugates and QD-A3 were first thoroughly cleaned of excess of free $A 3$ proteins by multiple filtrations. The concentrations of Au NP was first determined by inductively coupled plasma mass spectroscopy (ICP-MS). According to Dyer et al. the gold core of the purified AuNP-A3 was then dissolved in 3.7 $\mathrm{M} \mathrm{KCN}$, releasing the $\mathrm{A} 3$ proteins. The concentration of $A 3$ proteins initially bound to the AuNP was determined by fluorescence spectroscopy (Fig. S3). We found that A3-saturated AuNP, prepared with 100 molar equivalents of $A 3$, contain an average of 80 A3 per AuNP (see Figure S3), which is in good agreement with the migration saturation estimate (Table 1). In the case of QD-A3, the CdSe@ZnS core shell QD were dissolved in presence of an acidic $\mathrm{HCl}$ solution according to Debayle et al. The QD-A3 prepared from 100 molar equivalents of $A 3$ were found to contain an average of $20 \mathrm{~A} 3$ per QD. This latter observation is in agreement with a smaller affinity of the A3 protein for QD surface than for A $y_{j}$ surfacedsee

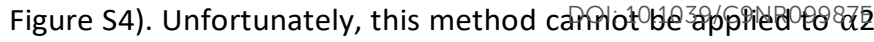
since its intrinsic fluorescence emission is too low to assess the concentration of $\alpha 2$ protein after NP dissolution.

To further assess to the specific binding between QD-grafted proteins and complementary proteins, A3 proteins are immobilized on Surface Plasmon Resonance (SPR) sensor chips and subjected first to a high flux of $Q D-\alpha 2$ and then to an influx of pure buffer. The SPR sensorgrams are shown in Fig. 3a. A strong positive association phase is observed in the case of the A3 coated surface. When the nanoparticles bound to the A3coated surface are washed, a reduction of the SPR response is observed indicating that dissociation occurs leading to a new equilibrium state. No association is observed during control experiments performed either by immobilizing the identical $\alpha 2$ protein or Bovine Serum Albumine (BSA). These observations demonstrate the ability of $Q D-\alpha 2$ to specifically bind to $A 3$
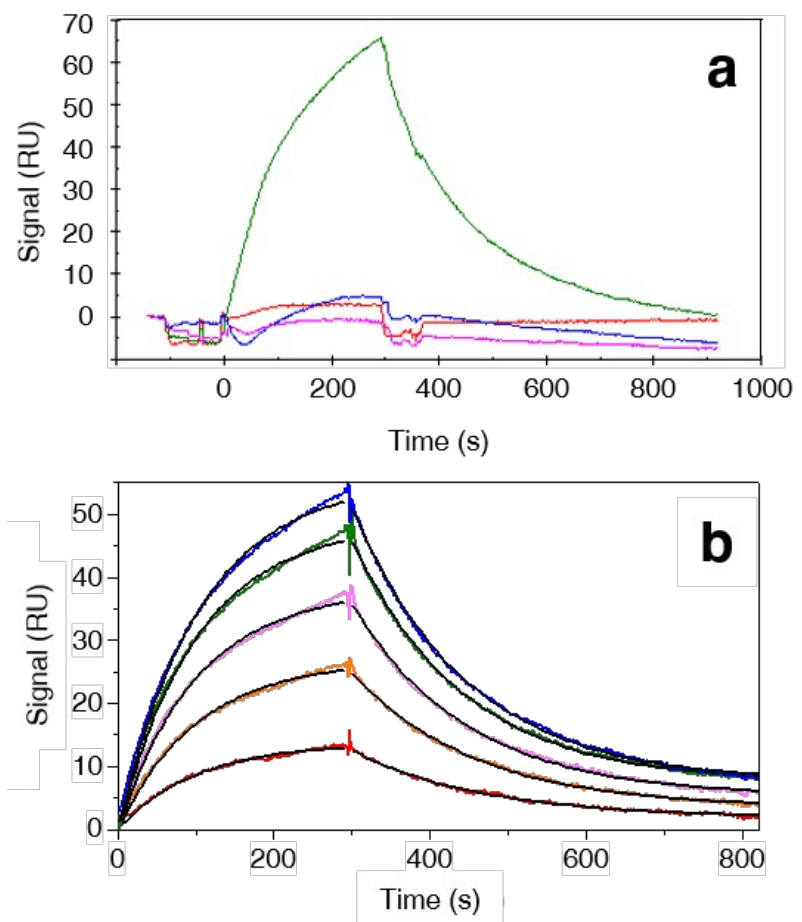

Fig. 3 QD- $\alpha 2$ affinity for A3 coated surface. (a) SPR sensorgrams during association and dissociation phases monitoring the interactions between $Q D-\alpha 2$ nanoparticles (2.3 nM) and immobilized protein surfaces: A3 (green curve), bovine serum albumin (blue curve), $\alpha 2$ (pink curve) and a bare surface (red curve). (b) SPR sensorgrams during association and dissociation phases monitoring the interactions between $\mathrm{A} 3$ immobilized surface and QD- $\alpha 2$ nanoparticles at different concentrations: $0 \mathrm{nM} ; 0.4 \mathrm{nM} ; 0.8 \mathrm{nM} ; 1.2 \mathrm{nM} ; 1.6 \mathrm{nM} ; 2.0 \mathrm{nM}$ and $2.4 \mathrm{nM}$ (from bottom to top). Solid black lines are exponential fits to the association and dissociation phases.

protein coated surface. To estimate the affinity constant $K_{D}$, the same experiment is performed with different QD- $\alpha 2$ concentrations as shown in Fig. $3 \mathrm{~b}$. The data are fitted with a 1:1 single exponential interaction model (Fig. 3b, black lines) in both association and dissociations phases, suggesting a single binding mechanism of $Q D-\alpha 2+A 3=Q D-\alpha 2 \bullet A 3$. The dissociation constant was extracted from three different approaches 


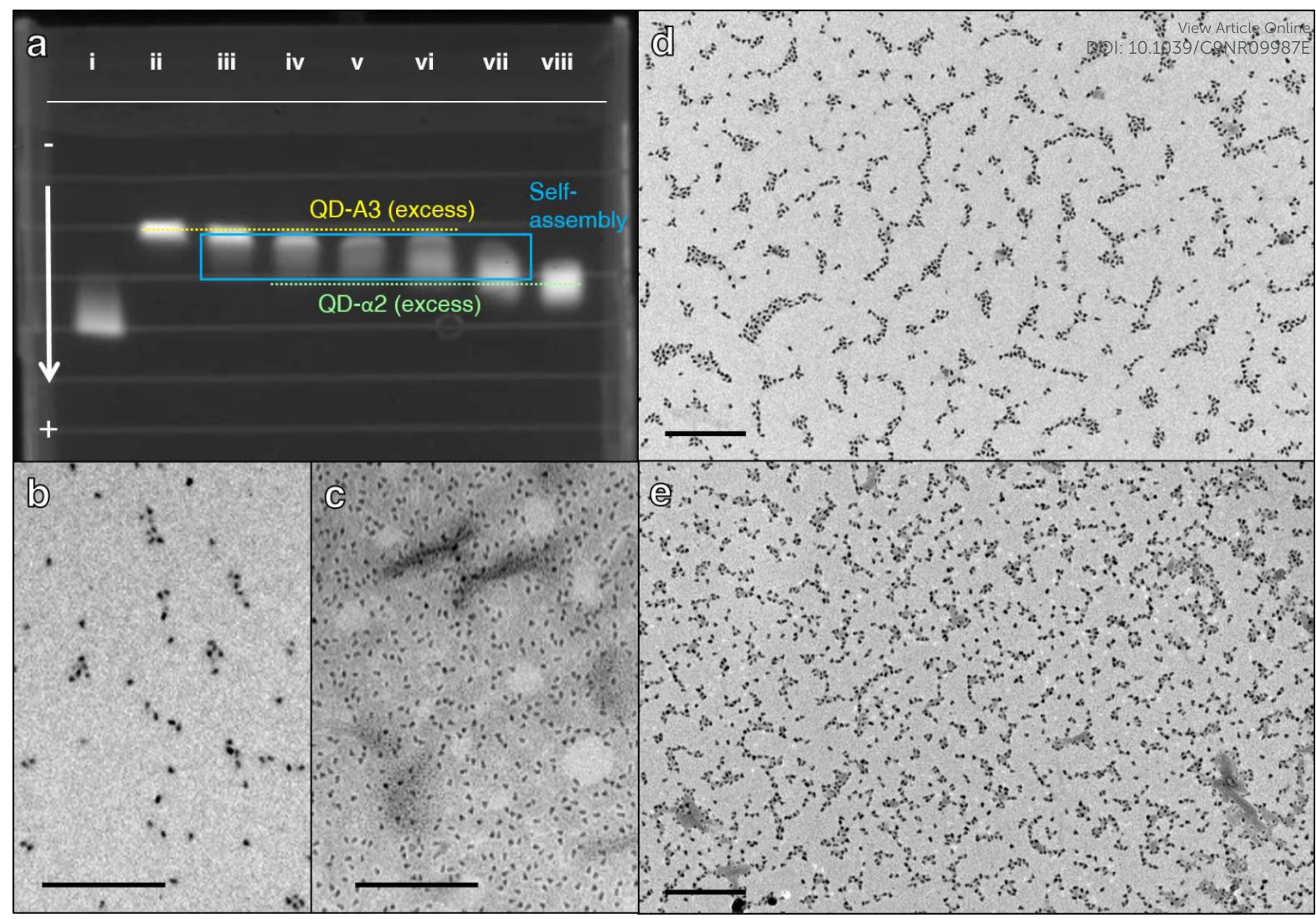

Fig. 4 (a) Fluorescence image of the agarose gel electrophoresis of pure QD-C5PEG4, QD-A3, mixtures of QD-A3 and QD- $\alpha 2$ at 5:1, 2:1, 1:1, 1:2 and 1:5 molar ratios respectively and QD- $\alpha 2$ in tracks i-vii respectively. TEM images of (b) pure QD-A3, (c) pure QD- $\alpha 2$, (d) 1:1 QD- $\alpha 2+$ QD-A3 mixture and (e) 1:5 QD- $\alpha 2+Q D-A 3$ mixture. Scale bars represent $100 \mathrm{~nm}$.

detailed in experimental part and supplementary section (Fig. S5). All the quantitative analysis consistently yield to $5 \mathrm{nM}$ dissociation constant similar to the one measured by ITC in free $\alpha 2 / A 3$ proteins pairs. ${ }^{22}$

The protein pair affinity is high enough to drive the selfassembly of protein-grafted QD when suspensions of QD- $\alpha 2$ and QD-A3 are incubated together. The electrophoretic migrations of the complementary mixtures of $Q D-\alpha 2$ and $Q D$ A3 (Fig. 4a, tracks iii-vii) are monotonously intermediate between those of pure protein-grafted QD (Fig. 4a, tracks ii and viii) as the molar ratio between the two populations is varied. The migration distances was found to directly depend on the composition of the mixture. A brighter spot was seen on the same side of the excess partner (top side for track iii and iv where QD-A3 is in excess; bottom side for tracks vii where QD$\alpha 2$ is in excess) superimposed with a broader central trail which dominates tracks $v$ and vi. The intermediate migrations observed for the complementary QD mixtures indicate a specific interaction that cannot be accounted for by simple superposition of non-interactive mixtures of the native suspensions. Zeta potential measurements confirm that the protein grafting results in a decrease of the net surface charge for the NP in agreement with the isoelectric points of the proteins (Table S1). The zeta potential of the complementary
QD mixtures cannot be extracted due to the increased polydispersity of the mixtures. Indeed TEM observations reveal the formation of spatially limited assemblies giving oligomers of nanoparticles that cannot be found in the original QD- $\alpha 2$ or QDA3 populations (Fig. 4). The effect of the larger effective size of the complementary QDs appears to be screen by the intermediate net charge which acts as the dominant factor maybe because the electrophoresis is performed with low agarose pourcentage gel. The statistical analysis of the number of QD per oligomers reveals a distribution of limited-sized oligomers with 2 to 30 QD per oligomers (see Figure 4a) in agreement with the relative low charge of bound $A 3$ protein at the surface of the QD (20 protein/QD) estimated from fluorescence titration (See Figure S6). These observations confirm that the specific interaction between the complementary QD results in new superstructures with intermediate net charge and larger effective size that can be maximized for QD-A3 : QD- $\alpha 2$ molar ratios around 1:1 to $1: 2 .{ }^{33}$ Small Angle X-ray Scattering (SAXS) experiments were performed to get more quantitative structural information on the QD self-assemblies and are summarized in Fig. 5. Pure QDA3 and pure QD- $\alpha 2$ suspensions produce a similar featureless SAXS pattern (Fig. 5a, black curve). On the contrary, the data of the equimolar QD-A3 / QD- $\alpha 2$ mixture exhibit a marked peak at 
$q=0,038 \AA^{-1}$ (Fig. 5a, blue curve). After baseline subtraction, this broad scattering is well fitted by a Gaussian function centered at $\boldsymbol{q}_{0}=0.0364 \AA^{-1}$ (Fig. 5a, inset). In the Debye-Scherrer theory, this feature is characteristic of a small crystal with a center-tocenter particle interdistance $d_{R X}=17.2 \mathrm{~nm}$. The full width of the peak $\Delta q_{0}$ is $0.0180 \AA^{-1}$ yields $N=q_{0} / \Delta q_{0} \sim 2$ QD-proteins, which suggests that this broad scattering originates in a pair correlation function between two QD and is attributed to the QD-A3• $\alpha 2-Q D$ elementary pair. ${ }^{31}$
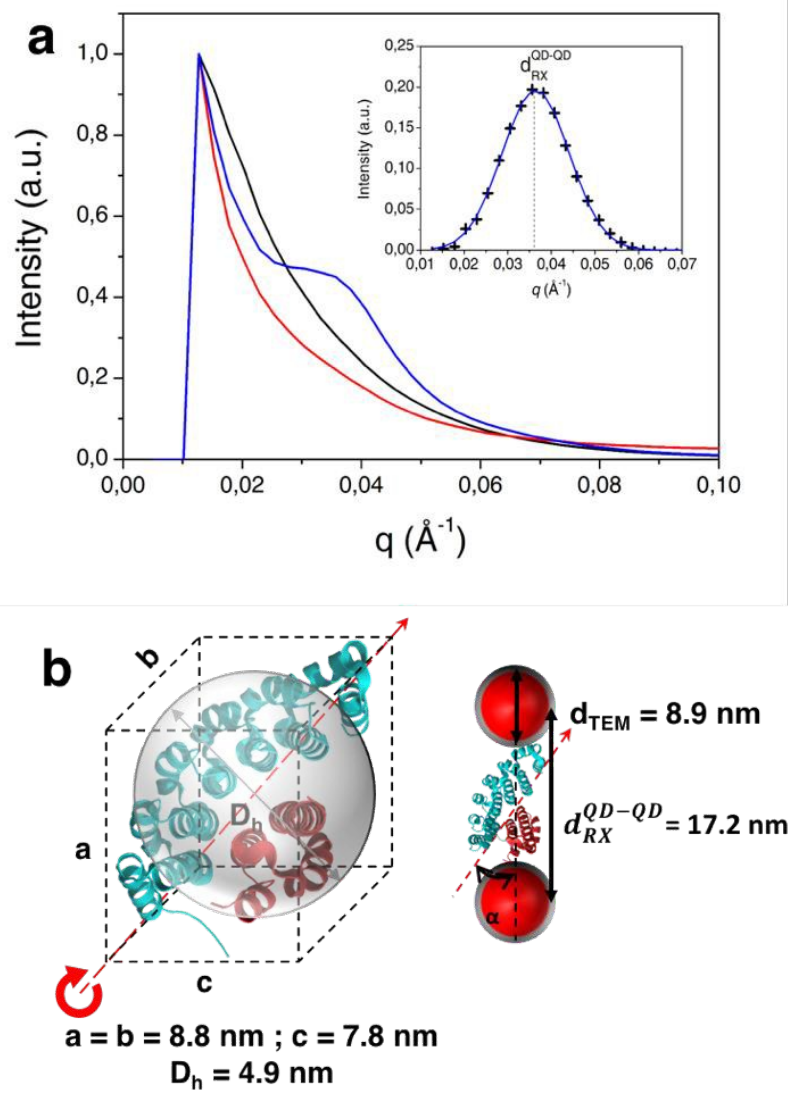

Fig. 5(a) SAXS data of QD-A3 (black curve) showing characteristic self-assembly signal when mixed with complementary QD- $\alpha 2$ (blue curve) and competition experiment run with an excess of free $\alpha 2$ protein (red curve). INSET: peaks of QD-A3/QD- $\alpha 2$ mixture and Gaussian fit (see text). (b) (left) Crystallographic data $(a, b, c)^{20}$ and hydrodynamical diameter $D_{h}$ of the A3- $\alpha 2$ protein complex; (right) Schematic view of the complementary $Q D$ arrangement including the QD diameter measured by TEM $\left(\mathrm{d}_{\mathrm{TEM}}\right)$ and the SAXS interdistance $\left(d_{R x}\right)$.

The QD diameter measured from TEM images is $8.9 \pm 1.4 \mathrm{~nm}$ (Fig. S2b), hence $d_{R x}=17.2 \mathrm{~nm}$ yields an interparticle distance of $8.3 \pm 1.4 \mathrm{~nm}$, that is in good agreement with the value of $7.6 \pm 2.6 \mathrm{~nm}$ obtained directly from TEM (Fig. S7). This gap region between two adjacent $Q D$ matches precisely the expected size of the A3- $\alpha 2$ protein complex (Fig. 5b). Hence both TEM and SAXS data strongly support the formation of QDQD self-assemblies driven by the protein pair complexation. Interestingly, when competition experiments are run by adding an excess of free $\alpha 2$ protein, the characteristic SAXS peak disappears (Fig. 5a, red curve), as expected from the entropic advantage of free protein over particle-bound protein inothe binding event. ${ }^{23,24}$ DOI: 10.1039/C9NR09987E

Beyond homogenous QD-QD or AuNP-AuNP assemblies, our approach allows to form hybrid self-assembled nanostructures that associate QD and AuNP with a precise control of the interparticle distance. Both protein-grafted $Q D$ and AuNP samples were prepared following the procedure described in Fig. 1. The surface density of proteins is adjusted by using 100 or 30 molar equivalents of proteins during the ligand exchange step. Several mixtures of QD-A3 and AuNP- $\alpha 2$ of different QD : AuNP molar ratio are produced with a fixed total nanoparticle concentration of $96 \mathrm{nM}$ (see Experimental Methods). In Fig. 6, TEM images reveal the formation of proteindriven hybrid self-assembly where QD and AuNP coexist and systematically alternate. Indeed, assemblies of increasing dimensions are observed within the mixtures of complementary A3-grafted $Q D$ and $\alpha 2$-grafted AuNP according to the nanoparticle:protein stoichiometry. Hybrid assemblies obtained from QD and AuNP with protein-saturated coating features very large assemblies (Fig. 6a, Fig. S8 and S9) while mixtures produced from nanoparticles with more moderate surface density of proteins contains much smaller assemblies comprising a few tens of nanoparticles (Fig. $6 \mathrm{~b}$ and $6 \mathrm{~g}$ ) down to trimers (Fig. 6c-e and Fig. S10). A closer examination shows that $>98 \%$ of QD and $>90 \%$ of AuNP are engaged in a self-assembled pair (Table S2), which qualitatively illustrate the high efficiency of the protein affinity driving force in this self-assembly. Control experiments consisting of either mixture of QD-A3, AuNP- $\alpha 2$ and an excess of free $\alpha 2$ proteins (Fig. S11) or mixture of non-

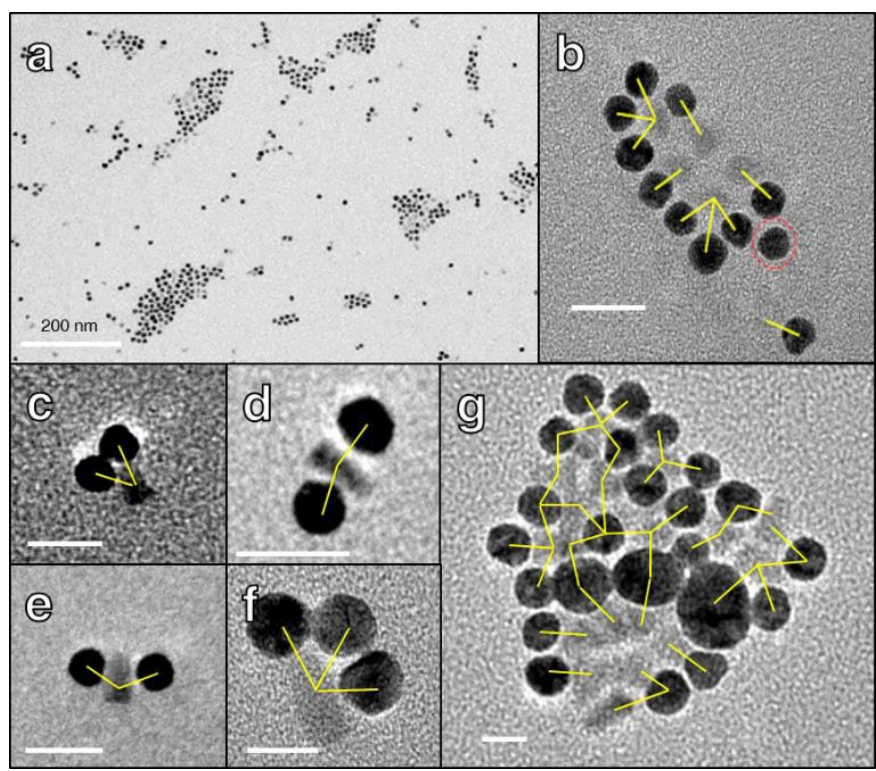

Fig. 6 TEM images of (a) large self-assemblies of QD-A3 and AuNP- $\alpha 2$ and (b-g) spatially limited self-assemblies QD-A3 and AuNP- $\alpha 2$. Scale bar is $20 \mathrm{~nm}$ for B and D. Scale bar is $10 \mathrm{~nm}$ for C. Yellow bars represent QD-AuNP pairs that are possibly linked by protein pairs. Red dotted circle indicates AuNP with no obvious link to QD.

complementary QD- $\alpha 2$ and AuNP- $\alpha 2$ (Fig. S12) present dispersed AuNP and QD with no significant association. 
Small Angle X-ray Scattering (SAXS) experiments performed on a (1:1) mixture of QD-A3 and AuNP- $\alpha 2$ suspensions with protein-saturated coating exhibit a characteristic peak at $q=0,0395 \AA^{-1}$ (Fig. 7, blue curve). After baseline subtraction, this broad scattering is well fitted by a Lorentzian function centered at $\boldsymbol{q}_{\boldsymbol{o}}=0.0387 \AA^{-1}$ (Fig. 7, inset). In the disordered crystal theory of Guinier, the Lorentzian shape indicates a disorder of second kind in a crystal which is liquid-like. This corresponds to the aggregate observed by TEM. The mean center-to-center particle interdistance $d_{R X}^{Q D-A u N P}=16.2 \mathrm{~nm}$. On the contrary pure QD-A3 (black curve) and AuNP- $\alpha 2$ (yellow curve) suspensions as well as the control competition (red curve) and reversibility (green curve) experiments on the equimolar QD-A3 / AuNP- $\alpha 2$ mixture produce featureless SAXS pattern (Fig.7). A surface-to-surface interdistance of 7.75 $\pm 1.15 \mathrm{~nm} \mathrm{~nm}$ is estimated from the QD-Au center-to-center interdistance $d_{R X}^{Q D-A u N P}$ and the NP diameters $\left(d_{T E M}^{A u}=8 \mathrm{~nm}\right.$, $d_{T E M}^{Q D}=8.9 \mathrm{~nm}$ ) (see Figure 7). Additional SAXS experiments performed with different sized QD (See Figure S13) and the same AuNP reveal the same behaviour and confirm a very welldefined interdistance. A surface-to-surface distance respectively of $9 \pm 1 \mathrm{~nm}$ for $Q D^{605}$ and $8.75 \pm 1 \mathrm{~nm}$ for $Q D^{545}$ is estimated from the center-to-center distances obtained by SAXS for green and orange QD (see Figure S14). As in the case of QD-QD superstructures, this value around $8 \mathrm{~nm}$ is in the

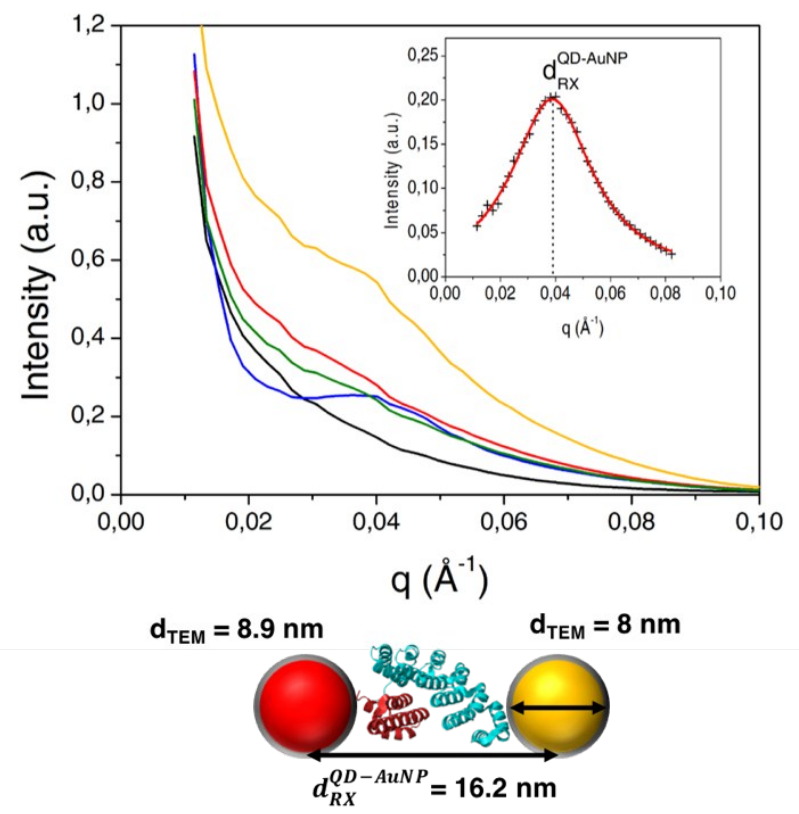

range of the $A 3 \bullet \alpha 2$ proteins complex size.

Fig. 7 SAXS data of showing a characteristic self-assembly signal when QD-A3 and AuNP- $\alpha 2$ are mixed together (blue curve). INSET: peaks of QD-A3/AuNP- $\alpha 2$ mixture and Lorentzian fit (see text). Pure QD-A3 (black curve) and AuNP- $\alpha 2$ (yellow curve) as well as competition experiments run with an excess of free $\alpha 2$ protein (red curve) and reversibility control experiment performed through the addition of free $\alpha 2$ protein (green curve) show no sign of organization. Schematic view of the complementary QD/AuNP arrangement including $Q D$ and $A u$ diameters measured by TEM and the center-to-center interdistance $\left(d_{R X}^{Q D-A u N P}\right)$.

Both SAXS and TEM experiments confirm that complementary and available surface-tethered proteins are necessary to induce the colloidal assembly. The mean surface-to-surface

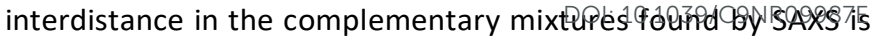
of $8 \mathrm{~nm}$ in agreement with the protein complex size.

In addition, the protein-driven assembly has a marked effect on the exciton-plasmon interaction inside the hybrid aggregates as illustrated in Fig. 8 and S15. When a suspension of QD-A3 is mixed with increasing amounts of non-complementary AuNPA3 (Fig. 8, grey bars) a gradual decrease in intensity is observed that can be almost entirely ascribed to relative dilution and some A3 dimerization at high AuNP-A3 molar fraction. When the AuNP are functionalized with $\alpha 2$ (Fig. 8, red bars), specific complementary interactions induce a much larger quenching of the luminescence, which is essentially suppressed for an equimolar mixture, i.e. when all QD and AuNP are potentially engaged in hybrid superstructures. The sub-10 $\mathrm{nm}$ interparticle distance seems to favor the QD (donor) to AuNP (acceptor) energy transfer and non-radiative decay over metal-enhanced fluorescence. ${ }^{35,36}$ Interestingly, an effect due to a modification of the local dielectric constant in the self-assembled structure

Mol\% of QD- $\alpha 2$

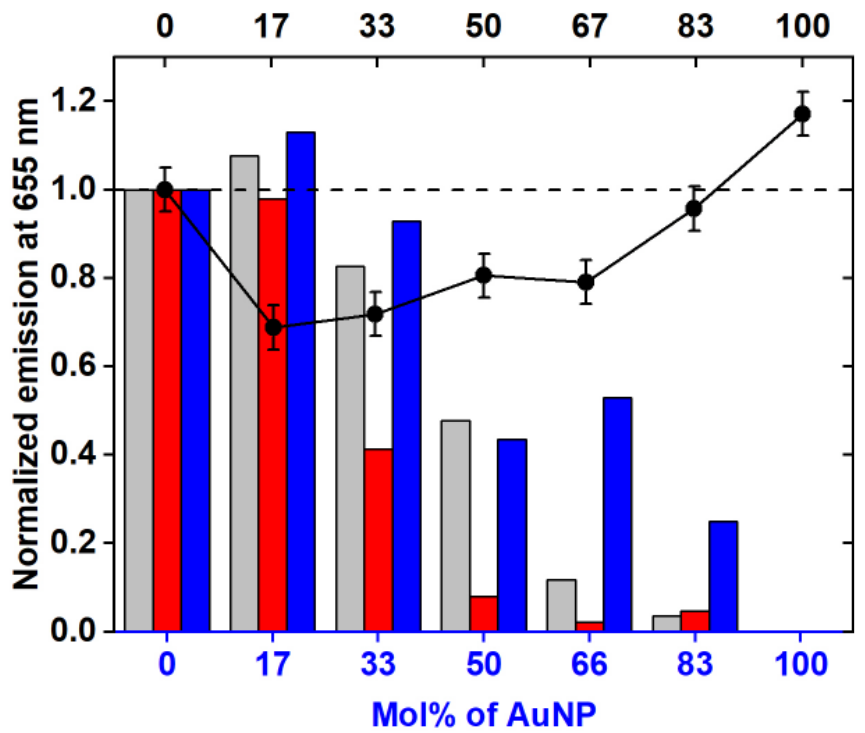

Fig. 8 Histograms showing the evolution of the QD-A3 fluorescence $\left(\lambda_{\mathrm{em}}=655 \mathrm{~nm}\right)$ in the presence of AuNP in with non-specific (AuNP-A3, grey), specific (AuNP- $\alpha 2$, red) or competitive (AuNP- $\alpha 2$ and excess $\alpha 2$, blue) conditions. Black circle data show the QDA3 fluorescence $\left(\lambda_{\text {em }}=655 \mathrm{~nm}\right)$ in the presence of specific QD- $\alpha 2$ using the same A3$\alpha 2$ protein pair. Fluorescence intensities are normalized to the value for pure QD-A3 (0 Mol\% of AuNP or QD- $\alpha 2$ ) by taking into account the dilution factor. The dashed line corresponds to the expected normalized fluorescence intensity for QD-A3 corrected from the dilution.

can be disregarded by comparing the emission of QD-A3• $\alpha 2$ AuNP mixtures to the equivalently specific but plasmon-free QD-A3 $\bullet \alpha 2-Q D$ case (Fig. 8, black circles). In the latter case, the luminescence decreases moderately as QD- $\alpha 2$ are introduced and form larger aggregates but it remains higher than $70 \%$ of the intensity value for pure QD-A3 and it increased back as soon as the $Q D-\alpha 2$ is in excess. The reduction in QD fluorescence observed in the hybrid assembly can not be solely ascribed to the assembly process or the modification of the scattering properties by an effective increase in local dielectric constant but might be also related to the plasmon-mediated non- 
radiative decay. Finally, when the protein-driven colloidal assembly is performed in the presence of a large excess of free $\alpha 2$, a competition is set for the $\alpha 2 \bullet A 3$ protein pair. It is expected that the small $\alpha 2$ protein will preferentially bind to QD-A3 resulting in a mixture where $Q D-A 3 \bullet \alpha 2$ coexist with AuNP- $\alpha 2$ with minimal interaction. The fluorescence of the mixture in competitive conditions (Fig. 8, blue bars) is indeed equal or higher than the fluorescence of the non-specific mixture. In particular, when the AuNP molar fraction is high, the binding of free $\alpha 2$ to form $Q D-A 3 \bullet \alpha 2$ seems to further limit the non-specific binding ( $\mathrm{A} 3$ dimerization), and the evolution of the luminescence is closer to the linear decrease expected for simple dilution. The evolution of the fluorescence for complementary interacting QD-A3 (with different emission wavelengths) and AuNP- $\alpha 2$ mixtures exhibits also a quenching as shown in Fig. S15. However, there is no simple correlation between the spectral overlap of the emission band and the plasmon band that would permit to discriminate the different contributions of the mechanisms (MET or FRET) involved in the observed coupling (see Figure S16).

\section{Conclusion}

To conclude, we have shown that high affinity pairs of artificial repeat proteins offer a unique platform to translate specific biomolecular interactions to functional colloidal selfassemblies. The main assets of our approach exploit (i) the very low (around $5 \mathrm{nM}$ ) dissociation constant, (ii) the pair specificity that makes it possible to develop, at will, orthogonal pairs for complex hybrid constructions and (iii) the rigid structure of the proteins and their complexes that enables a strategy towards topologically determined 3D assembly. In this work, we focus on creating and characterizing superstructures comprising proteincoated semi-conductor QD only and their plasmonic hybrid extension by coupling to gold nanoparticles. Using, gel electrophoresis and SPR measurements, we demonstrate a generic approach to graft any alpha-repeat protein on the surface of the quantum dots without altering the biorecognition. The self-assemblies have been structurally analysed by TEM and SAXS, which reveal that the surface-tosurface nanoparticle interdistance is set around $8 \mathrm{~nm}$ by the size of the protein pair. As the 3D structure of the $A 3 \bullet \alpha 2$ complex is known, one can modulate the interdistance between anchored nanoparticles and thus their optical coupling by extending the proteins with additional motifs without destabilizing the binding interface with $\alpha 2$. Given their modular nature and the geometry of the $\alpha 2$ helices arrangement, alphaRep proteins could be engineered, either by changing the number of motifs along a chosen protein, each motif resulting in an additional $1 \mathrm{~nm}$ distance. We also observe that the extent of the superstructures can be tuned by adjusting the surface density of grafted proteins. The higher protein : nanoparticle stoichiometry, the larger is the size of the resulting selfassembled superstructure. Conversely, QD-QD or hybrid QD-Au oligomers form when the nanoparticles carry a few bound proteins, giving access to model systems such as QD-Au-QD trimers ${ }^{37}$. Finally, the luminescence of the $Q D$ is quenched when

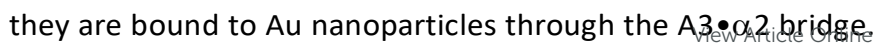

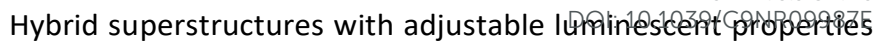
should be produced by tuning the spectral overlap between the excitonic and plasmonic resonances making our approach a versatile tool for biosensing applications.

\section{Conflicts of interest}

There are no conflicts to declare.

\section{Acknowledgements}

The Agence Nationale de la Recherche (ANR, contract $N^{\circ}$ ANR16-CE09-0027-02 HYPNAP and Contract N ${ }^{\circ}$ ANR-14-CE08-0004 ARTEMIS) funded this work. We are endebted to the Region Bretagne for the financial support of the MF's phD fellowship.

\section{Notes and references}

1 S. Bidault, A. Devilez, V. Maillard, L. Lermusiaux, J.-M. Guigner, N. Bonod and J. Wenger, ACS Nano, 2016, 10, 4806-4815.

2 A. O. Govorov, G. W. Bryant, W. Zhang, T. Skeini, J. Lee, N. A. Kotov, J. M. Slocik and R. R. Naik, Nano Lett., 2006, 6, 984994.

3 P. D. Howes, S. Rana and M. M. Stevens, Chem. Soc. Rev., 2014, 43, 3835-3853.

4 T. Sannomiya and J. Vörös, Trends Biotechnol., 2011, 29, 343351.

5 A. Klinkova, R. M. Choueiri and E. Kumacheva, Chem. Soc. Rev., 2014, 43, 3976-3991.

6 N. S. Thakur, G. Patel, V. Kushwah, S. Jain and U. C. Banerjee, ACS Appl. Bio Mater., 2019, 2, 349-361.

7 J. Liu, J. Mantell, N. D. Bartolo and M. R. Jones, Small, 2019, 15, 1804267.

8 N. Zhou, V. López-Puente, Q. Wang, L. Polavarapu, I. PastorizaSantos and Q.-H. Xu, RSC Adv., 2015, 5, 29076-29097.

9 E. Henry, A. Dif, M. Schmutz, L. Legoff, F. Amblard, V. MarchiArtzner and F. Artzner, Nano Lett., 2011, 11, 5443-5448.

10 T. Bizien, J.-C. Ameline, K. G. Yager, V. Marchi and F. Artzner, Langmuir, 2015, 31, 12148-12154.

11 Z. Tang, N. A. Kotov and M. Giersig, Science, 2002, 297, 237.

12 G. C. des Francs, A. Bouhelier, E. Finot, J. C. Weeber, A. Dereux, C. Girard and E. Dujardin, Opt. Express, 2008, 16, 17654-17666.

13 D. Sun, Y. Tian, Y. Zhang, Z. Xu, M. Y. Sfeir, M. Cotlet and O. Gang, ACS Nano, 2015, 9, 5657-5665.

14 W.-W. Zhao, P.-P. Yu, Y. Shan, J. Wang, J.-J. Xu and H.-Y. Chen, Anal. Chem., 2012, 84, 5892-5897.

15 J. M. Slocik, A. O. Govorov and R. R. Naik, Supramol. Chem., 2006, 18, 415-421.

16 K. K. Haldar, T. Sen and A. Patra, J. Phys. Chem. C, 2010, 114, 4869-4874.

17 G. Mandal, M. Bardhan and T. Ganguly, J. Phys. Chem. C, 2011, 115, 20840-20848.

18 Y. Fu, J. Zhang and J. R. Lakowicz, Chem. Commun., 2009, 313315.

19 J. Lee, T. Javed, T. Skeini, A. O. Govorov, G. W. Bryant and N. A. Kotov, Angew. Chem. Int. Ed., 2006, 45, 4819-4823.

20 E. Oh, M.-Y. Hong, D. Lee, S.-H. Nam, H. C. Yoon and H.-S. Kim, J. Am. Chem. Soc., 2005, 127, 3270-3271.

21 A. Urvoas, A. Guellouz, M. Valerio-Lepiniec, M. Graille, D. Durand, D. C. Desravines, H. van Tilbeurgh, M. Desmadril and P. Minard, J. Mol. Biol., 2010, 404, 307-327. 
22 A. Urvoas, M. Valerio-Lepiniec and P. Minard, Trends Biotechnol., 2012, 30, 512-520.

23 A. Guellouz, M. Valerio-Lepiniec, A. Urvoas, A. Chevrel, M. Graille, Z. Fourati-Kammoun, M. Desmadril, H. van Tilbeurgh and P. Minard, PLOS ONE, 2013, 8, e71512.

24 K. L. Gurunatha, A. C. Fournier, A. Urvoas, M. Valerio-Lepiniec, V. Marchi, P. Minard and E. Dujardin, ACS Nano, 2016, 10, 3176-3185.

25 A. Dif, E. Henry, F. Artzner, M. Baudy-Floc'h, M. Schmutz, M. Dahan and V. Marchi-Artzner, J. Am. Chem. Soc., 2008, 130, 8289-8296.

26 G. Frens, Nat. Phys. Sci., 1973, 241, 20-22.

27 T. Bizien, P. Even-Hernandez, M. Postic, E. Mazari, S. Chevance, A. Bondon, C. Hamon, D. Troadec, L. Largeau, C. Dupuis, C. Gosse, F. Artzner and V. Marchi, Small, 2014, 10, 3707-3716.

28 M. Debayle, E. Balloul, F. Dembele, X. Xu, M. Hanafi, F. Ribot, C. Monzel, M. Coppey, A. Fragola, M. Dahan, T. Pons and N. Lequeux, Biomaterials, 2019, 219, 119357.

29 J. Jasieniak, L. Smith, J. van Embden, P. Mulvaney and M. Califano, J. Phys. Chem. C, 2009, 113, 19468-19474.

$30 \mathrm{X}$. Liu, M. Atwater, J. Wang and Q. Huo, Colloids Surf. B Biointerfaces, 2007, 58, 3-7.

31 A. Dif, F. Boulmedais, M. Pinot, V. Roullier, M. Baudy-Floc'h, F. M. Coquelle, S. Clarke, P. Neveu, F. Vignaux, R. L. Borgne, M. Dahan, Z. Gueroui and V. Marchi-Artzner, J. Am. Chem. Soc., 2009, 131, 14738-14746.

32 V. Roullier, S. Clarke, C. You, F. Pinaud, G. Gouzer, D. Schaible, V. Marchi-Artzner, J. Piehler and M. Dahan, Nano Lett., 2009, 9, 1228-1234.

33 R. L. Rich and D. G. Myszka, J. Mol. Recognit., 2008, 21, 355400.

34 C. Chi, F. Vargas-Lara, A. V. Tkachenko, F. W. Starr and O. Gang, ACS Nano, 2012, 6, 6793-6802.

35 K. Okamoto, M. Funato, Y. Kawakami and K. Tamada, $J$. Photochem. Photobiol. C Photochem. Rev., 2017, 32, 58-77.

36 O. Kulakovich, N. Strekal, A. Yaroshevich, S. Maskevich, S. Gaponenko, I. Nabiev, U. Woggon and M. Artemyev, Nano Lett., 2002, 2, 1449-1452.

37 B. Rousseaux, D. Dzsotjan, G. Colas des Francs, H. R. Jauslin, C. Couteau and S. Guérin, Phys. Rev. B, 2016, 93, 045422. 


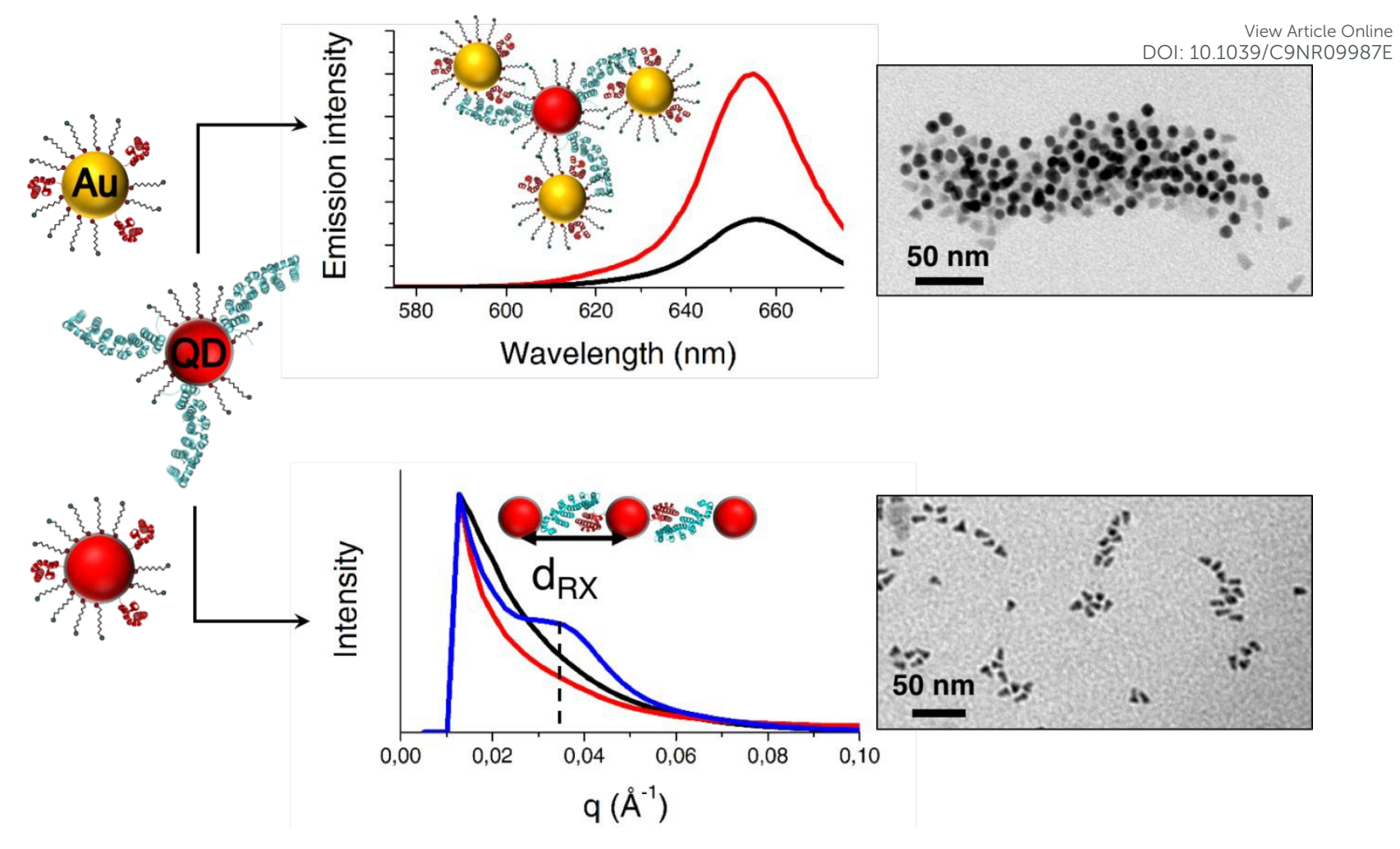

